\title{
The Costs of Industry-Sponsored Drug Trials in Canada
}

\author{
Dat T. Tran ${ }^{1,2}$ (D) Ilke Akpinar ${ }^{1} \cdot$ Philip Jacobs ${ }^{3}$
}

Published online: 10 July 2019

(c) The Author(s) 2019

\begin{abstract} cal trials (CTs) in Canada. (\$Can757.5 million) had the highest costs. were valued at \$Can2.1 billion.

\section{Key Points for Decision Makers}

There are several ways to estimate the costs of a drug clinical trial (CT). The method used should be appropriate for the purpose of the study, whether it is to measure the replacement value of publicly or privately funded healthcare, estimate investment in new technologies or conduct an economic evaluation.

The total costs of drug CTs in Canada amounted to 2.1 billion Canadian dollars for all industry-sponsored trials that ended in 2016.
\end{abstract}

Objective The objective of this study was to estimate the provincial and nationwide costs of industry-sponsored drug clini-

Methods We used the Aggregate Analysis of ClinicalTrials.gov (AACT) database, and included all industry-sponsored drug CTs that were conducted in Canada and completed in 2016. We estimated the costs of the study drugs using the market price. Estimates of the costs of management and patient services were based on industry contracts.

Results The sample included 394 CTs that were conducted in 2039 facilities in Canada and provided services for 20,126 Canadian enrollees. Two-thirds of the CTs (277 of 394) were in the non-cancer category. On average, the drug costs per patient were 89,680 Canadian dollars (\$Can) during the lifespan of the CTs, and were higher in cancer CTs than in non-cancer CTs (\$Can216,876 vs. \$Can65,274). The total costs of industry-sponsored drug CTs completed in 2016 was \$Can2093.7 million. Drug costs accounted for the majority of this total (\$Can1804.9 million). Ontario (\$Can781.2 million) and Quebec

Conclusion The costs of industry-sponsored drug CTs completed in 2016 when measured in terms of market prices in Canada

Electronic supplementary material The online version of this article (https://doi.org/10.1007/s41669-019-0161-0) contains supplementary material, which is available to authorized users.

Philip Jacobs

pjacobs@ualberta.ca

1 Institute of Health Economics, Edmonton, AB, Canada

2 Faculty of Pharmacy and Pharmaceutical Sciences, University of Alberta, Edmonton, AB, Canada

3 Department of Medicine, University of Alberta, 13-103 Clinical Sciences Building, 11350-83 Avenue, Edmonton, AB T6G 2G3, Canada

\section{Introduction}

Clinical trials (CTs) are critical components in the public assessment of new technologies. Industry-sponsored CTs can also play a role in relieving the healthcare cost burden through the trial-based care received by trial participants.

In industry-sponsored drug CTs, the sponsor usually pays for the drug, patient consultation and procedure costs, as well as the fees for ethics reviews and initial setups (e.g. laboratory, pharmacy). Current estimates of the costs of CTs in Canada come from an annual survey of industry conducted by the Patented Medicine Price Review Board (PMPRB); respondents to this survey report $\mathrm{CT}$ costs according to the cost of manufacturing, as defined in the Canada Income Tax Act [1]. The manufacturer's cost is not the same as the price that would be paid for by the funders of healthcare (i.e. the insurer's or consumer's retail price). Nevertheless, there is a cost attributable to all healthcare services received by CT participants [2].

Currently, little is known about the costs of industrysponsored drug CTs in large and diverse health systems. Accordingly, we estimated the provincial and nationwide costs of industry-sponsored drug CTs in Canada. 


\section{Methods}

\subsection{Study Design and Data Sources}

We conducted an analysis using the Aggregate Analysis of ClinicalTrials.gov (AACT) database [3], which provides rich data elements on each CT, such as the number of enrollees, start and completion dates, treatment regimen, location(s) and funding. The AACT database has been used previously in research [2].

All industry-sponsored drug CTs that were conducted in Canada (either in Canada only or in Canada and other countries) and completed in 2016 (regardless of start date) were included. CTs with zero enrolment were excluded.

\subsection{Variables of Interest}

The main variable that we wished to estimate was the sum of the drug, management and patient services costs of industry-sponsored drug CTs completed in 2016 in Canada. For convenience, we refer to this variable as 'total costs' for the remainder of this paper. Other variables of interest included the distribution of the costs by trial arms, type of CT (cancer or non-cancer) and province.

\subsection{Number of Enrollee Estimates}

The AACT database provides only the total number of enrollees for each CT, and therefore we had to estimate the number of enrollees in Canadian facilities in the multinational CTs. To obtain the number of enrollees in each Canadian facility within a CT, we assumed that patient enrolment would be equal for each facility in a multinational or multisite CT. We then calculated the number of enrollees in each province within a CT by multiplying the total number of enrollees in the CT by the number of facilities in that province, and then divided by the total number of participating facilities in the CT.

\subsection{Drug Costs}

We used a previously reported algorithm to estimate the costs of the study drugs $[2,4]$. Briefly, we first searched for each drug's market price in the Alberta Drug Benefit List (ADBL) [5]. If a price was not found there, we searched the US Department of Veterans Affairs Pharmaceutical Prices (VAPP) database [6]. If there was no price in either the ADBL or the VAPP database, we used the Medscape website to find an alternative drug that was equivalent in indication, and used the relevant alternative drug for pricing. If an alternative drug could not be identified, we used the price of the drug used for patients in the control arm. As the last resort, we used the listed price of the relevant chemical compound on the MedChemExpress and Selleckchem.com websites [7, 8]. As the US drug price could be 3.4 times higher than that of the Canadian price, we adjusted for this price difference and converted the US price to the Canadian price using the Bank of Canada exchange rate (\$US1 $\approx 1.298$ Canadian dollars [\$Can] on 7 August 2018) $[9,10]$.

Using the treatment regimen from the CT protocols, we multiplied the average dosage by the treatment length and drug price to calculate the drug costs per patient during the lifespan of a CT. The total drug costs for each trial in each province were then derived by multiplying the per patient drug costs during the lifespan of that trial by the number of enrollees in that province. The methods for calculating the costs are shown in Box 1, where we provide a step-by-step example of the cost calculation for the trial NCT01133743, which is one of the trials included in the analysis [11]. Finally, we summed the drug costs of all trials in all provinces to calculate the total, Canada-wide CT drug costs.

\subsection{Management and Patient Service Billings}

The AACT database does not provide cost data. We estimated management and patient service billings for each CT based on a previous report on the economic contribution of industry-sponsored drug CTs in Alberta [2]. The management billings (e.g. start-up costs, document archival, advertisement) were estimated at \$Can7180 and \$Can18,721 for each cancer and non-cancer CT, respectively, in each province where it was conducted; the ethics fee specifically was estimated at $\$ \mathrm{Can} 2500$ for each CT, in each province. Patient service billings (e.g. screening, procedures, consultations, treatments of adverse events, laboratory tests, imaging procedures) were estimated at $\$$ Can 11,909 and \$Can17,350 per patient for cancer and non-cancer CTs, respectively. We adjusted these patient service billing estimates for each province according to the province's hourly wage rate for health professions relative to those of Alberta in 2016 [12]. Similar to our methods for estimating drug costs, we then calculated the total patient service billings in each province by multiplying the per-patient service billings by the number of enrollees in that province. Management and patient service billings in all provinces were then summed to calculate the total, Canada-wide CT non-drug costs.

\subsection{Statistical Analysis}

We calculated per-enrollee drug costs during the lifespans of the CTs, and reported the means of these values $(95 \%$ confidence interval $[\mathrm{CI}]$ ), by trial arms (experiment or control) and type of CT (cancer or non-cancer). We reported the total economic values in determined values for Canada 
Box 1 Step-by-step cost calculation of the trial NCT01133743. ADBL Alberta Drug Benefit List, $C T$ clinical trial, $P O$ oral, VAPP Veterans Affairs Pharmaceutical Prices, $\$$ Can Canadian dollars
Trial summary: This was a phase II, non-randomized, single institution study in symptomatic, previously untreated Chronic Lymphocytic Leukemia patients. All patients received the study drug, lenalidomide, given PO daily continuously on a 28-day cycle.

Drug regimen: lenalidomide (average dose: $10 \mathrm{mg}$ PO daily continuously); dexamethasone (12 mg PO daily on days 1-7, 14, and 21).

$\mathrm{N}$ patients $=31$ patients, with a median of 18 cycles or a total of 434 cycles for all patients.

Step 1: Drug costs

1) Lenalidomide

A box of lenalidomide (28 capsules $2.5 \mathrm{mg}$ ) cost US\$16,660.59 (VAPP); Exchange rate: 1 CAN\$ $=0.7702$ US\$; US drug price was 3.36 times higher than Canadian price. Therefore, 1 lenalidomide capsule $2.5 \mathrm{mg}$ cost $16,660.59 \times(1 / 0.7702) \times(1 / 3.36) / 28=\mathrm{CAN} \$ 229.93$. The daily costs were CAN $\$ 229.93 /$ cap $X 4$ caps $=$ CAN $\$ 919.7$

Lenalidomide drug costs $=434$ cycles ${ }^{*} 28$ days ${ }^{*}$ CAN $\$ 919.7=$ CAN $\$ 11,176,194$

2) Dexamethasone

Dexamethasone tablet $4 \mathrm{mg}$ cost CAN $\$ 0.3046$ (ADBL). Therefore, the costs for dexamethasone in a cycle were: CAN $\$ 0.3046 /$ tablet $X 3$ tablets $X 9$ days $=$ CAN $\$ 8.22$

Dexamethasone drug costs $=434$ cycles ${ }^{*}$ CAN $\$ 8.22=$ CAN $\$ 3,569$

Total drug costs for this study = CAN $\$ 11,176,194+$ CAN $\$ 3,569=$ CAN $\$ 11,179,763$

( CAN\$360,638 per patient)

Step 2: Management and patient services billings

This trial was conducted in 1 site in Ontario.

Ethics review fee: CAN\$2,500

Management billings: CAN $\$ 7,180$ (for cancer CT) for implementation in a province

Patient services billings: CAN\$11,909/ patients (for cancer CT); adjusted for difference in health occupation hourly wage rate between Alberta (CAN\$34.29) and Ontario (CAN\$29.63), the total patient services billings for this trial are: CAN\$11,909 X 31 patients $X 29.63 / 34.29=$ CAN\$319,008.

\section{Step 3: Total trial costs}

Total costs $=$ Total drug costs + Ethics review fee + Management billings + Patient services billings $=11,179,763+2,500+7,180+319,008=$ CAN $\$ 11,508,451$ and for each province. All monetary values were presented in current Canadian dollars. We also calculated the length of each CT in months from start date to end date, and reported the means of these lengths $(95 \%$ CI). Population estimates from Statistics Canada were used to calculate total costs per capita for each province [13].

\subsection{Sensitivity Analyses}

In the main analysis, we had adjusted for the US and Canada drug price differences at market exchange rates (ratio=3.4), which is similar to the price differences at purchasing power parity (ratio =3.3) [10]. We therefore conducted an analysis where we recalculated the drug costs using the unadjusted US price, to examine the impact on total drug costs. In addition, in the main analysis, we had assumed that the number of enrollees would be equal across facilities in a multinational CT. We therefore conducted another analysis where the number of enrollees in Canadian facilities was $25 \%$ lower and $25 \%$ higher than the average number of enrollees per facility in the CTs that were multinational.

All analyses were performed using STATA $^{\circledR}$ version 14 (Stata Corp., College Station, TX, USA) and Microsoft Excel $^{\circledR}$ version 2016 (Microsoft Corp., Redmond, WA, USA). The study did not require ethics approval.

\section{Results}

A total of 400 industry-sponsored drug CTs were completed in 2016 in Canada. After excluding six CTs that had zero enrolment, the final sample included 394 CTs conducted in 2039 facilities across the ten provinces. Of these, 60 CTs 
were conducted in Canada only and 334 CTs were conducted in both Canada and other countries. Two-thirds of the CTs (277 of 394) were in the non-cancer category and provided services for approximately 17,000 patients, while the rest (117 of 394) were in the cancer category and provided services for more than 3000 patients (see Table 1).

The mean lengths of the CTs were 41.2 (95\% CI 37-45.4) and 31.3 (95\% CI 28.6-34) months for cancer and non-cancer CTs, respectively.

\subsection{Drug Costs}

A total of 375 drugs were used in the CTs (the list of drugs is presented in the Electronic Supplementary Material Appendix). The ADBL, VAPP database and website (MedChemExpress and Selleckchem.com) prices were used for 135 (36\%), 174 (46.4\%) and 66 (17.6\%) drugs, respectively. Approximately 28\% (111 of 394) of the CTs involved biologic/biosimilar products, which accounted for $17 \%$ (64 of 375) of the drugs.

On average, the drug costs per patient were \$Can89,680 during the lifespans of the CTs, and were higher in cancer CTs than in non-cancer CTs (\$Can216,876 vs. \$Can65,274; $p<0.001)$ and in the experimental arm than in the control $\operatorname{arm}(\$ C a n 132,537$ vs. \$Can3375; $p<0.001)$ (see Table 1).

\subsection{Total Trial Costs}

Overall, the total costs of industry-sponsored drug CTs in 2016 was \$Can2093.7 million. Drug costs accounted for the majority of this total (\$Can1804.9 million); cancer and non-cancer CTs contributed \$Can737.4 million and \$Can1356.3 million, respectively. Ontario (\$Can781.2 million) and Quebec (\$Can757.5 million) had the highest CT costs because of the large number of CTs conducted as well as the large number of enrollees in those provinces (see Table 2). Newfoundland and Labrador had the highest value per capita (\$Can116), followed by Quebec (\$Can91) and New Brunswick (\$Can65) (see Fig. 1).

Except for Prince Edward Island, which had only one cancer CT, New Brunswick had the highest proportion of costs from cancer CTs (89.6\%); Ontario, which had the highest overall costs from industry-sponsored drug CTs, had the same proportion of costs from cancer CTs as the national average (35\%) (see Fig. 2).

\subsection{Sensitivity Analyses}

Using the unadjusted US VAPP database drug prices led to an additional \$Can696.7 million in drug costs for all industry-sponsored drug CTs completed in 2016 in Canada. Varying patient enrolment in the Canadian sites within the 334 multinational CTs, from $25 \%$ less than the average to $25 \%$ higher than the average, resulted in a range of Canadian enrollees between 16,043 and 24,182. Accordingly, the total costs of industry-sponsored drugs CTs in 2016 in Canada ranged from \$Can1612.8 million to \$Can2593.9 million (Table 3).

\section{Discussion}

Our study identified 394 industry-sponsored drug CTs that were completed in 2016. These CTs provided care to more than 20,000 enrollees in Canada. We estimated that the Canadian healthcare systems would have had to spend an additional \$Can2.1 billion if these industry-sponsored CTs had not taken place and had not provided healthcare services to the trial participants and the experimental drugs had been approved. Ontario and Quebec had the highest absolute trial
Table 1 Summary of drug costs in all clinical trials (2016)

\begin{tabular}{lllcc}
\hline Variable & $\begin{array}{l}\text { Clinical } \\
\text { trials }(n)\end{array}$ & Total enrolees $(n)^{\mathrm{a}}$ & $\begin{array}{l}\text { Canadian } \\
\text { enrolees }(n)^{\mathrm{b}}\end{array}$ & $\begin{array}{l}\text { Value per enrollee }(\$ \mathrm{Can})^{\mathrm{b}} \\
\text { [mean }(95 \% \mathrm{CI})]\end{array}$ \\
\hline All trials & \multirow{2}{*}{394} & 315,014 & 20,126 & $89,680(85,147-94,213)$ \\
Experimental arm & & 203,282 & 13,448 & $132,537(123,482-141,592)$ \\
Control arm & & 111,732 & 6678 & $3375(2864-3887)$ \\
Non-cancer drug trials & 277 & 268,099 & 16,886 & $65,274(61,078-69,471)$ \\
Experimental arm & & 171,361 & 11,039 & $98,451(89,672-107,231)$ \\
Control arm & & 96,738 & 5847 & $2637(2090-3183)$ \\
Cancer drug trials & \multirow{2}{*}{117} & 46,915 & 3240 & $216,876(199,795-233,957)$ \\
Experimental arm & & 31,921 & 2409 & $288,732(258,892-318,571)$ \\
Control arm & & 14,994 & 831 & $8573(7168-9978)$ \\
\hline
\end{tabular}

CI confidence interval, $\$$ Can Canadian dollars

${ }^{\mathrm{a}}$ The total number of enrollees was from the Access to Aggregate Content of ClinicalTrials.gov (AACT) database

${ }^{\mathrm{b}}$ Number of Canadian enrollees and drug costs per enrollee were estimated 
Table 2 Summary of industrysponsored drug clinical trial costs in Canada (2016)

\begin{tabular}{llllllllllll}
\hline Variable & Canada & AB & BC & MB & NB & NL & NS & ON & PE & QB & SK \\
\hline Number of trials $^{\mathrm{a}}$ & 394 & 133 & 146 & 52 & 28 & 29 & 58 & 316 & 1 & 239 & 23 \\
Number of facilities & 2039 & 174 & 223 & 56 & 34 & 46 & 61 & 875 & 1 & 544 & 25 \\
Number of enrollees & 20,126 & 1317 & 2069 & 385 & 290 & 651 & 485 & 9434 & 10 & 5142 & 343 \\
Drug costs & 1804.9 & 117.5 & 153.5 & 45.3 & 44.9 & 51.5 & 37.7 & 650.8 & 0.1 & 687.9 & 15.7 \\
Experiment arm & 1782.4 & 115.8 & 151 & 44.8 & 44.6 & 50.6 & 37.3 & 641.2 & 0.1 & 681.6 & 15.4 \\
Control arm & 22.5 & 1.7 & 2.5 & 0.5 & 0.3 & 1 & 0.4 & 9.6 & 0 & 6.3 & 0.3 \\
Management and patient & 288.7 & 23.6 & 31.4 & 6.2 & 4.3 & 10 & 7.4 & 130.4 & 0.1 & 69.6 & 5.7 \\
$\quad$ service billings & & & & & & & & & & & \\
Ethics review & 2.6 & 0.3 & 0.4 & 0.1 & 0.1 & 0.1 & 0.1 & 0.8 & 0 & 0.6 & 0.1 \\
Management billings & 15.7 & 2.0 & 2.3 & 0.8 & 0.4 & 0.5 & 0.9 & 4.8 & 0 & 3.7 & 0.3 \\
Patient service billings & 270.5 & 21.2 & 28.8 & 5.3 & 3.8 & 9.4 & 6.3 & 129.4 & 0.1 & 65.3 & 5.4 \\
Total costs (\$Can, million) & 2093.7 & 141.1 & 184.9 & 51.5 & 49.2 & 61.5 & 45.1 & 781.2 & 0.2 & 757.5 & 21.5 \\
\hline
\end{tabular}

$A B$ Alberta, $B C$ British Columbia, $M B$ Manitoba, $N B$ New Brunswick, $N L$ Newfoundland and Labrador, $N S$ Nova Scotia, $O N$ Ontario, $P E$ Prince Edward Island, $Q B$ Quebec, $S K$ Saskatchewan, \$Can Canadian dollars

${ }^{a}$ Total number of trials in all provinces is greater than the number of trials in Canada because a particular trial could take place in more than one province

${ }^{\mathrm{b}}$ Management and patient service billings were estimated from a previous report (Tran et al. [2])

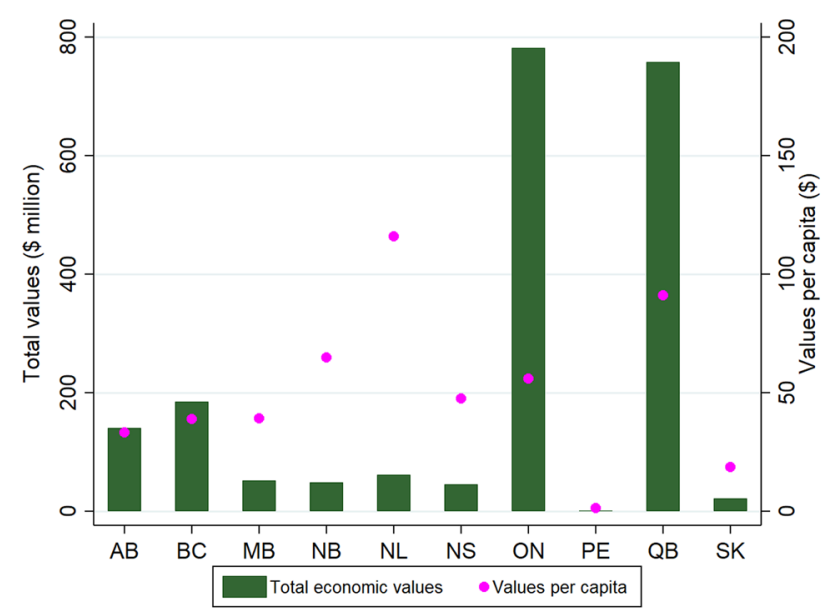

Fig. 1 Summary of total costs (in Canadian dollars [\$Can]) for industry-sponsored drug clinical trials in Canada, by province (2016). $A B$ Alberta, $B C$ British Columbia, $M B$ Manitoba, $N B$ New Brunswick, $N L$ Newfoundland and Labrador, $N S$ Nova Scotia, $O N$ Ontario, $P E$ Prince Edward Island, $Q B$ Quebec, $S K$ Saskatchewan

costs, while Newfoundland and Labrador had the highest value per capita. Using unadjusted US drug prices led to an increase of \$Can 0.7 billion in drug costs, while varying patient enrolment by $25 \%$ around the point average corresponded to a range of total costs between \$Can1.6 billion and $\$$ Can 2.6 billion. Our timelines cover all trials that were completed in 2016. Each year, new trials start and ongoing ones reach completion. We therefore assume that our results could be a rough approximation for 1 year's worth of economic activity.

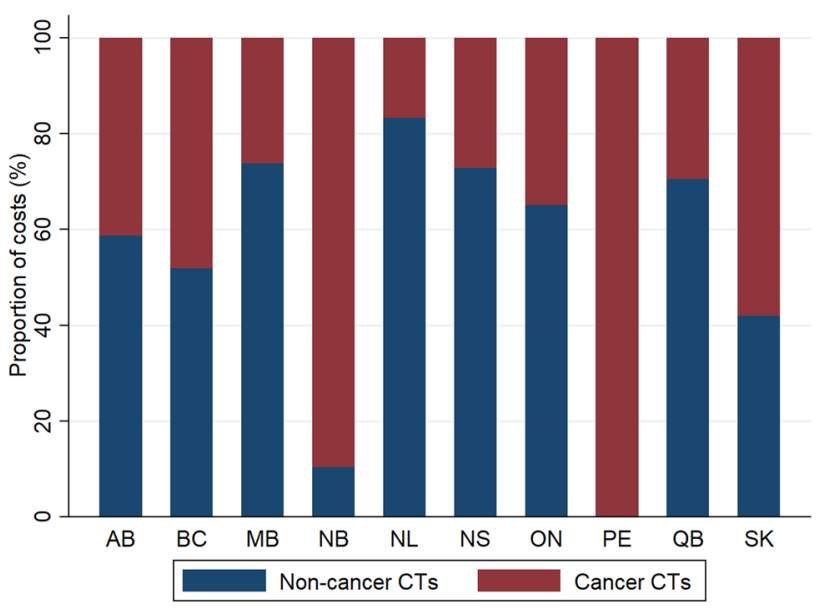

Fig. 2 Distribution of total costs for cancer versus non-cancer clinical trials in Canada, by province (2016). $A B$ Alberta, $B C$ British Columbia, $C T s$ clinical trials, $M B$ Manitoba, $N B$ New Brunswick, $N L$ Newfoundland and Labrador, $N S$ Nova Scotia, $O N$ Ontario, $P E$ Prince Edward Island, $Q B$ Quebec, $S K$ Saskatchewan

We found that the cost contribution from industry was heavily concentrated in Ontario and Quebec, which has also been reported by the PMPRB. However, the PMPRB reported a lower research and development $(R \& D)$ expenditure of \$Can918 million from drug companies in Canada in 2016, equalling the reported percentage of R\&D-to-sales of $4.4 \%$ [14]. The PMPRB uses a valuation method set by Canada's taxation agency, Revenue Canada, that reports costs of raw materials and labour costs of production and depreciation. This valuation method is appropriate when comparing the use of resources between industries, and is 
Table 3 Sensitivity analysis results

\begin{tabular}{llll}
\hline Variable & $\begin{array}{l}\text { Unadjusted } \\
\text { US drug } \\
\text { price }\end{array}$ & $\begin{array}{l}\text { Patient enrolment at } \\
\text { Canadian facilities }\end{array}$ \\
\cline { 3 - 4 } & & $\begin{array}{l}\text { 25\% less } \\
\text { than aver- } \\
\text { age }\end{array}$ & $\begin{array}{l}25 \% \text { higher } \\
\text { than aver- } \\
\text { age }\end{array}$ \\
\hline Canadian enrolees $(n)$ & 20,126 & 16,043 & 24,182 \\
Drug costs (\$Can, million) & 2501.6 & 1371 & 2238.9 \\
Experiment arm & 2456.2 & 1353.4 & 2211.4 \\
Control arm & 45.4 & 17.6 & 27.5 \\
Management and patient & 288.7 & 241.8 & 355.1 \\
services billings (\$Can, & & & \\
million) & & & \\
Total costs ${ }^{\mathrm{a}}$ (\$Can, million) & 2790.3 & 1612.8 & 2593.9 \\
\hline
\end{tabular}

$\$$ Can Canadian dollars

${ }^{a}$ Total costs may not be exactly the same as sum of drug costs and management and patient services billings because of rounding

an important indicator of the volume of economic activity devoted to R\&D. However, it is not appropriate for all purposes because it does not provide an indication of the value of services received by patients through CTs, which is the purpose of our measure.

The number of trial enrollees and corresponding costs of industry-sponsored clinical research are substantial compared to the contributions from public and non-profit organisations in Canada, which were estimated at \$Can235 million in 2016 [15]. This underscores the importance of the private sector in providing research activities in Canada. In addition, CTs not only help foster scientific advancement and healthcare innovation, but they also provide opportunities for early and faster access to critical therapies for patients. This is particularly important for CTs with expanded access, where patients receive free treatment until a drug is licensed and/or where the trialled drug is the only treatment option available. In this case, the benefit gained could be much higher than the findings in this study.

Although this study provides novel data on the costs of industry-sponsored drug CTs in Canada, it has limitations. First, we included open-label (expanded access) CTs in the study sample, but there may have been CTs with an unreported open-label phase that came into effect at the end of a CT. Therefore, the actual costs may be higher than those we measured. Second, we did not have the exact number of enrollees in the Canadian facilities in multinational CTs, and assumed equal enrolment across facilities in these CTs. In addition, we did not have a Canadian price for every drug, and resorted to other price sources. However, the range of total costs calculated through the sensitivity analyses should capture the uncertainty associated with these assumptions. Lastly, we estimated management and patient service billings from contracts of a small number of industry-sponsored drug CTs conducted in Northern Alberta [2] and we adjusted these for wage differentials between provinces. We assumed that patterns of care are similar throughout the country. If care patterns differ between provinces, then these differences would create cost differences.

We should also point out that our analysis does not provide information about health outcomes. In most multiplearm trials, one arm comes out on top-trial participants who receive care in that arm get the best outcomes. However, as in the real world, those receiving care in the other trial arm(s) typically receive care that is still beneficial, just not as beneficial as care in the best-performing arm. Our analysis does not address which trial participants get the best outcomes, but rather what the costs are for the care that the participants receive.

\section{Conclusions}

When valued using a market price method, the costs of industry-sponsored drug CTs are substantial. In addition to the creation of knowledge, these trials play an important role in alleviating the healthcare cost burden in Canada. Appropriate policy should be in place to foster industry investments in clinical research to advance both scientific and economic merits.

Author Contributions PJ and DTT conceptualized the study. DTT and IA searched the Access to Aggregate Content of ClinicalTrials.gov (AACT) database for trial details and carried out the costing analyses. DTT drafted the manuscript. All authors contributed to the writing of the manuscript and critically reviewed the manuscript for intellectual content.

\section{Compliance with Ethical Standards}

Funding Innovative Medicines Canada funded the research for this study with an unrestricted grant to the Institute of Health Economics.

Conflict of Interest Dat T. Tran, Ilke Akpinar and Philip Jacobs have no conflict of interest to declare.

Data Availability Statement The datasets analysed during the current study are available in the public domain: (1) the Access to Aggregate Content of ClinicalTrials.gov (AACT) dataset was downloaded on 15 July 2018 and is available at https://aact.ctti-clinicaltrials.org/; (2) the Alberta Interactive Drug Benefit List was downloaded on 7 August 2018 and is available at https://www.ab.bluecross.ca/dbl/publicatio ns.html; and (3) the US Department of Veterans Affairs Pharmaceutical Prices file was downloaded on 7 August 2018 and is available at https://www.va.gov/opal/nac/fss/pharmPrices.asp.

Open Access This article is distributed under the terms of the Creative Commons Attribution-NonCommercial 4.0 International License (http://creativecommons.org/licenses/by-nc/4.0/), which permits any noncommercial use, distribution, and reproduction in any medium, 
provided you give appropriate credit to the original author(s) and the source, provide a link to the Creative Commons license, and indicate if changes were made.

\section{References}

1. Government of Canada. Income Tax Act (R.S.C., 1985, c. 1 (5th Supp.)). Ottawa, 1985.

2. Tran DT, Akpinar I, Fedorak R, et al. The economic contribution of industry-sponsored pharmaceutical clinical trials. J Pharm Pharm Sci. 2017;20:407-14.

3. Clinical Trials Transformation Initiative. Improving public access to Aggregate Content of ClinicalTrials.gov. https://aact.ctti-clini caltrials.org/. Accessed 15 Jul 2018.

4. Akpinar I, Jacobs P, Tran TD. Forecasting pharmaceutical prices for economic evaluations when there is no market: a review. Pharmacoecon Open. 2017;1:65-8.

5. Alberta Health. Interactive Drug Benefit List (iDBL). https:// www.ab.bluecross.ca/dbl/publications.html. Accessed 7 Aug 2018.

6. Office of Acquisition and Logistics (OPAL), U.S. Department of Veterans Affairs. Pharmaceutical prices. https://www.va.gov/opal/ nac/fss/pharmPrices.asp. Accessed 7 Aug 2018.

7. Medchem Express. http://www.medchemexpress.com/. Accessed 9 Aug 2018.
8. Selleckchem. http://www.selleckchem.com. Accessed 9 Aug 2018.

9. Bank of Canada. Exchange rates. http://www.bankofcanada.ca/ rates/exchange/. Accessed 7 Aug 2018.

10. Patented Medicine Prices Review Board: annual report 2017. Ottawa: Patented Medicine Prices Review Board; 2017

11. Chen CI, Paul H, Snitzler S, et al. A phase 2 study of lenalidomide and dexamethasone in previously untreated patients with chronic lymphocytic leukemia (CLL). Leuk Lymphoma. 2019;60:980-9.

12. Statistics Canada. Table: 14-10-0307-01 (formerly CANSIM 2820152). Employee wages by occupation, annual. https://www 15 0.statcan.gc.ca/t1/tbl1/en/cv.action?pid=1410030701\#timeframe. Accessed 28 Jun 2018.

13. Statistics Canada. Table: 17-10-0005-01 (formerly CANSIM 0510001). Estimates of population, by age group and sex for July 1 , Canada, provinces and territories. http://www5.statcan.gc.ca/cansi $\mathrm{m} /$ pick-choisir?lang $=$ eng $\& \mathrm{p} 2=33 \& \mathrm{id}=0510001$. Accessed $28 \mathrm{Feb}$ 2018.

14. Patented Medicine Price Review Board. annual report 2016. Ottawa: Patented Medicine Prices Review Board; 2016.

15. Akpinar I, Tran DT, Jacobs P. Publicly funded clinical research in Canada. Healthc Manage Forum. Epub 2019 Jul 2. https://doi. org/10.1177/0840470419827320. 